1 Patterns of change in material use and material efficiency in the

2 successor states of the former Soviet Union

3

4 James West ${ }^{\mathrm{a}, \mathrm{b}}$ (corresponding author)

5 E jim.west@csiro.au $\quad \mathrm{T}+61262464390 \quad \mathrm{M}+61400737644$

6 CSIRO Ecosystem Sciences, GPO Box 1700, Canberra ACT 2601, Australia

7

8 Heinz Schandl ${ }^{\mathrm{a}, \mathrm{c}}$

9 E heinz.schandl@csiro.au

10

11 Fridolin Krausmann ${ }^{\mathrm{d}}$

12 E Fridolin.Krausmann@aau.at

13

14 Jan Kovanda ${ }^{\mathrm{e}}$,

15 E Jan.Kovanda@czp.cuni.cz

16

17 Tomas Hak ${ }^{\mathrm{e}}$

18 E Tomas.Hak@czp.cuni.cz

19

20

$21{ }^{\mathrm{a}}$ CSIRO Ecosystem Sciences, Social and Economic Sciences Program, Black

22 Mountain Laboratories, Acton, 2601 ACT, Australia

23

$24{ }^{\mathrm{b}}$ Griffith University, Environmental Futures Research Institute, 170 Kessels Road,

25 Nathan, 4111 Qld, Australia 
1 c Australian National University, School of Sociology, Canberra, ACT 2601, Australia 2

3 d Institute of Social Ecology, Vienna, Alpen Adria Universitaet Klagefurt-Wien-Graz,

4 Vienna, Austria

5

6 ' Charles University Environment Center, U Krize 8, 15800 Prague 5, Jinonice,

$7 \quad$ Czech Republic

8

9 


\section{Patterns of change in material use and material efficiency in the successor} states of the former Soviet Union

James West ${ }^{\mathrm{a}, \mathrm{b}}$, Heinz Schandl ${ }^{\mathrm{a}, \mathrm{c}}$, Fridolin Krausmann ${ }^{\mathrm{d}}$, Jan Kovanda ${ }^{\mathrm{e}}$, Tomas Hak ${ }^{\mathrm{e}}$.

${ }^{a}$ CSIRO Ecosystem Sciences, Social and Economic Sciences Program, Black

Mountain Laboratories, Acton, 2601 ACT, Australia

${ }^{\mathrm{b}}$ Griffith University, Environmental Futures Research Institute, 170 Kessels Road, Nathan, 4111 Qld, Australia

${ }^{\mathrm{c}}$ Australian National University, School of Sociology, Canberra, ACT 2601, Australia

${ }^{\mathrm{d}}$ Institute of Social Ecology, Vienna, Alpen Adria Universitaet Klagefurt-WienGraz, Vienna, Austria

${ }^{\mathrm{e}}$ Charles University Environment Center, U Krize 8, 15800 Prague 5, Jinonice, Czech Republic

\section{Abstract}

The successor states of the former Soviet Union present a unique opportunity to study the changes in the socio-metabolic profile of a cohort of nations which underwent a radical and contemporaneous shift in economic system. That change was from being regions within an economically integrated, centrally planned whole, to being independent nations left to find their own place in the global economic system. The situation of these nations since the dissolution of the Soviet Union provides a rare experiment, in which we might observe the influence of the 
different starting conditions of each nation on the development path it subsequently followed, and the attendant socio-metabolic profiles which resulted. Here we take the opportunity to examine patterns for the region as a whole, and for three individual countries. We also examine the relative importance of three different drivers of material consumption using a version of the IPAT framework. Finally, an area for follow on investigation was suggested by a significant positive correlation observed between the economic growth of individual successor states, and the degree to which they improved their material productivity. This latter is of potential importance in assessing whether dematerialization acts primarily to accelerate or retard economic growth.

\section{Introduction}

This study examines trends in material use and material efficiency for a region, Eastern Europe, the Caucasus and Central Asia (EECCA) which is composed of 12 countries which together accounted for the bulk of the former Soviet Union (the Baltic states are not included). A newly established database is used for this purpose, covering the period 1992 to 2008. The database has been constructed applying the economy wide material flows accounting (EW-MFA) methodology in a manner identical or very similar to that used for studies on a number of individual nations and global regions e.g. Gierlinger and Krausmann (2012), Kovanda and Hak (2008), Krausmann et al. (2009), Krausmann, Gingrich and Nourbakhch-Sabet (2011), Schandl and West (2010), West and Schandl (2013). This greatly facilitates valid comparisons between this region and those dealt with 
previously, and the data presented here makes a valuable contribution to extending consistent EW-MFA coverage of world regions ${ }^{1}$.

Inter-regional comparisons however are not the main purpose of this study. The focus here is instead on the opportunity to examine the socio-metabolic paths taken by the EECCA region as a whole, and three of its constituent nations, subsequent to the economic shock delivered by the dissolution of the former Soviet Union. This is the first time that material flow accounts for this region have been made available. They demonstrate the impact on natural resource use of the economic transition from centrally planned to market based economies. Earlier research has looked at Eastern European economies e.g. Kovanda and Hak (2008) which compared the Czech Republic, Hungary and Poland, however this study goes beyond previous findings and examines economies that were initially part of the same national economy i.e. the former Soviet Union. In addition to the dissolution of the Soviet Union and the integrated, centrally planned economy it had provided, the period 1992-2008 also encompassed external change of great importance to the successor states. Perhaps the most important external change was the reinvigoration of global economic growth which attended the increasing industrialization of Asia's population giants from the beginning of the $21^{\text {st }}$ Century. This led to massive increases in demand for primary materials (Schandl and West 2010), so extractive industries generally became much more profitable in the latter half of the period studied. This presumably made the path of developing a primary

1 Historically the MFA approach used for this study was one of two systems employed to organize environmental accounts at the national and international scale and in accordance with economic accounts. MFA was largely promoted by the Organization of Economic Cooperation and Development (Haberl et al. 2004) and is essentially a flow account of natural resources. The complement is the System of Economic and Environmental Accounts (SEEA) of the United Nations (Bartelmus 2007) which focuses on stock changes in natural resources and built assets. For MFA the science and policy community has reached broad agreement on the methodologies to be employed (Fischer-Kowalski et al. 2011) and more recently MFA has become an integrated part of the SEEA c.f European Commission et al. (2012). 
resource exports sector more attractive to those countries which had that option, while simultaneously eroding the competitiveness of any existing industries which used these resources inefficiently.

For this study, the overarching framework through which the evolving patterns of material flows and material productivity are viewed is that of socio-metabolic transitions, described in work such as Krausmann et al. (2008) and Schandl et al. (2009), and social-ecological regime change (Fischer-Kowalski and Haberl 2007, Krausmann et al. 2008). A social-ecological regime denotes the relationship of economic and social systems to the natural relations that determine resource availability in society. Metabolism has become a genuinely interdisciplinary concept used in sociology and biology alike, with socio-economic metabolism applying to the labour processes, technical systems, and infrastructure which maintain the material and energy requirements of a social system (Schandl and Schulz 2001), the metabolic processes of the "anthroposphere" as dealt with by Baccini and Brunner (1991). Metabolic transitions are large scale reconfigurations of the socio-economic system, and including changes in its relationship to the natural environment, relationships which are often highly interdependent and perhaps co-evolutionary (Weisz 2011). Using these concepts as an analytical framework allows us to establish information systems that cover all aspects of economic activity including the resource use and emissions that fuel and result from economic activity.

Economic development in the EECCA countries prior to 1992 was as regions ${ }^{2}$ of the USSR, interacting mainly with each other as members of the same centrally

2 Regions in the same nation probably best describes the functional role of individual Soviet Socialist Republics, even though they were nominally independent republics. 
planned economy. The USSR also had preferential economic links to a number of other centrally planned economies through the Council for Mutual Economic Assistance (Comecon), but otherwise was not well integrated into the broader global trading system. From 1991 on, the successor states to the USSR had to function as independent nations, competing in a global economy. It is important to note however that while the USSR was only officially dissolved in 1991, a contraction of economy, reflected in decreasing materials flows, was underway by the late 1980s (Schaffartzik et al., forthcoming). Similar contractions in material flows for other countries in the years prior to their turning away central planning have been recorded in other research e.g. in Kovanda and Hak (2011). While this contraction had been in train well before 1992, commencing during the period of perestroika, 1992 forms an appropriate beginning to the time series for this study as it is the first year for which most successor states have separate statistics for most materials.

This paper is structured as follows: A brief description of the methodology used to construct the underlying database is provided in section 2 , with a much more detailed technical annex provided as supporting information. Section 3 describes and illustrates salient points about material flows and aspects of resource efficiency for the region as a whole, then for three individual focus countries. The drivers of material flows are then discussed within the context of an IPAT framework. Section 4 provides a general discussion and conclusions, and also suggests further research to follow up on an apparent link between growth and material intensity found for this region. 
It is important to note that this paper deliberately uses previously well established and standardized methodologies where possible. Novelty of methodology was not an aim, and we make no claim to it. The main value of this study lies instead in the specific analyses of material flows and productivity patterns themselves. The most important aspect of this has been placing the observed resource use trajectories into context against the very specific and highly unusual, shared recent economic history of this region on the one hand, and the very different resource endowments of the individual nations on the other. This enables us to then explore what the divergent patterns observed indicate about constraints on socio-metabolic transitions and the development paths open to different nations, and the possible role of material productivity in this.

Methods used to establish material flow accounts have become been increasingly standardized in recent years, to facilitate inter-country and inter-regional comparisons. Both the methods and the underlying base data sets used to prepare the EW-MFA accounts for the EECCA region were essentially identical to those employed previously to assemble the database used in West and Schandl's (2013) analysis of material flows in Latin America and the Caribbean. The reader is thus referred to the methods and data sources section of that paper for a good summary of the database synthesis methods used here. Alternatively, a highly detailed account of the procedures used is contained in the the Technical Annex on EECCA MFA Database, attached as supporting information to this paper.

To analyse the drivers of material use, a variant of the Impact = Population $\mathrm{x}$ Affluence $x$ Technology (IPAT) framework is used. The method used is again 
identical to that employed in West and Schandl (2013), to which the reader is also referred for a brief description, and further onward references if required.

The GDP measure used throughout this study was exchange rate based constant year 2000 \$US, sourced from (World Bank 2012). We prefer to use exchange rate based GDP rather than PPP for assessing resource efficiency as it emphasises the international value placed on the economic activity, rather than the ability to consume locally. Exchange rate based measures also remain stable over time in relative terms, regardless of whether the base year used, in contrast to PPP measures, where countries can undergo major retrospective changes in relative GDP as the PPP methodology used is periodically updated.

\section{Results and Discussion}

\subsection{Trends in Material Use in Eastern Europe, the Caucasus, and Central Asia} Placed in a Global Context

Figure 1 shows the relatively small size of the EECCA region's domestic materials consumption (DMC) in the world context. The region's share of global DMC decreased from $10.5 \%$ to $5.6 \%$ over the period. Material flows for the region are best discussed after subdividing the time series data into two periods, the immediate post-Soviet era contraction, and the period of expansion which began in the late 1990s. From almost 4.5 billion tonnes in 1992, DMC fell rapidly to just 2.6 billion tonnes at its low point in 1998 , and then began to increase steadily to 4.0 
billion tonnes by 2008 , a contraction of some $12 \%$ when taken over the full period. This compares to total growth for the rest of the world of $74 \%$ over the same period, a compounding annual growth rate of 3.5\%. Given EECCA region's small share of global DMC (5.6\% in 2008) over the period there is little difference between values for the rest of the world (i.e. excluding the EECCA region), and total World figures.

\section{<Insert Figure 1 around here>}

Figure 2 shows that DMC per capita for the EECCA region in 1992, at 15.8 tonnes, was high compared to the 7.4 tonne World average. During the period of contraction this fell rapidly, almost to convergence with the World figure of at 8.5 tonnes per capita in 1998 , at which point it grew rapidly again to be $34 \%$ higher than the average for the World by 2008. DMC per capita had still not returned to late Soviet era levels by 2008, however growth from 1998 to 2008 was very dynamic, at $4.4 \%$ compounding, almost identical to that seen in the rapidly growing Asia-Pacific region over the same period (UNEP 2013b). Furthermore the onset of the Global Financial Crisis (GFC) seems to have had little impact on the region in aggregate, in contrast to the marked slowdown in the rest of the world's growth. This same pattern appeared in the Asia-Pacific (UNEP 2013b), and in a comparable study for Latin America (UNEP 2013a), and further supports the view of the GFC as an event largely confined to developed western countries, at least in its initial stage. We will see below that there is considerable nuance at the individual country level. 
Figure 3 shows domestic extraction (DE) over the period 1992 to 2008, disaggregated into four major categories, for the EECCA region. The pattern seen might be interpreted as economic restructuring during the post-Soviet era contraction having a disproportionate effect on those sectors most reliant on internal demand, while demand remained strong in export oriented sectors. Construction materials, for example, decreased 63\% between 1992 and 1997, while fossil fuels, and metal ores and industrial minerals decreased by only $24 \%$ and $20 \%$ respectively on 1992 levels.

It is noteworthy that Figure 3 indicates relative shares of the different major categories of materials remained broadly consistent when materials demand reexpanded. This differs from the pattern typically observed when countries experience a rapid expansion in DMC per capita as a result of transitioning from biomass-based advanced agrarian societies, to mineral and fossil fuel-based industrial societies. The classic socio-metabolic transition, described in FischerKowalski and Haberl (2007), is characterized by a strong decrease in the relative share of biomass in the total mix. This pattern was clearly observed in earlier studies for the Asia-Pacific region in Schandl and West (2010), and for the Latin America and Caribbean region in West and Schandl (2013). The pattern observed for the EECCA region might be explained by an industrialized society undergoing an economic contraction, then re-expanding into an already established, industrialized economic structure. The mix of mineral inputs to an industrialized economy can vary widely, depending on the detail of economic structure and technologies employed, the mix of industries developed (including the size of the services sector), and the technologies adopted. The EECCA mix is much heavily weighted towards fossil fuels, metal ores and industrial minerals in comparison to 
that seen for the EU-15 group reported for example in Weisz et al.(2004), which much more weighted towards construction minerals.

The degree of consistency in the relative shares of different material categories at the beginning and end of the period is interesting, in that it does not indicate any large-scale 'reprimarization' of the region over the post-Soviet period ${ }^{3}$. This is despite the large-scale rationalization of state-owned manufacturing which occurred over the period. As discussed later, this perhaps unexpected outcome may just indicate a need to analyse EW-MFA measures at a higher level of resolution, and also take materials efficiency gains into account.

\section{<Insert Figure 3 around here>}

Figure 4 shows net exports of fossil fuels for the period 1992 to 2008 growing at a compounding rate of $7.3 \%$ p.a., while the region simultaneously becomes a minor exporter of biomass. Net exports of metal ores and industrial minerals grew rapidly at $6.0 \%$ p.a. from 1996 to $2006^{4}$, while net trade in construction minerals was insignificant.

The low relative levels of net exports of fossil fuels over the main period of the post-Soviet era contraction, observable in the physical trade balance (PTB) in Figure 4 , indicates that there was only a modest shift from local consumption of fossil fuels and redirection to export markets over that period. Figure 3 showed that

3 The term reprimarization has usually been employed in the context of Latin America e.g. UNEP (2011), and refers to restructuring an economy away from import replacement/substitution manufacturing industries back towards a focus on increasing exports of primary commodities.

4 Time series data on metal ores and industrial minerals between 1991 and 1996 are too sporadic to permit detailed analysis for that period. 
domestic extraction (DE) of fossil fuels remained relatively high through the contraction period, in comparison to other materials ${ }^{5}$. Taken together, these two observations imply that domestic demand for fossil fuels was relatively inelastic (this does not hold for all individual successor nations, see section on focus countries below). The main period of expansion in fossil fuel exports actually took place during the re-expansionary phase, from the late 1990s. The expansion in fossil fuel exports was contemporaneous with massive growth of DMC of fossil fuels in the Asia-Pacific region. The EECCA region placed an additional 350 million tonnes p.a. of fossil fuels onto the world market between 1998 and 2008, while the total consumption of fossil fuels in the Asia-Pacific increased by roughly 2.3 billion tonnes. This complementarity echoes that described in West and Schandl (2013) regarding the expansion of metal ores production in Latin America, and rapid growth in metal ores demand from the Asia-Pacific region.

One factor which should be taken into account when interpreting PTB and DMC trajectories over time is that different categories of primary materials undergo very different degrees of concentration between initial extraction from the environment, and the form in which they are typically traded as crude commodities. The importance of this issue is described in detail in Schandl and West (2012).The main point is that the resources apparently "consumed" by an economy, as measured by DMC, will vary greatly depending on the type of commodities the economy uses, and the stage of the processing at which they are exported. Most importantly, apparent consumption measured by DMC can have little relationship to the point of final use ${ }^{6}$. This is especially so for some major classes of metal ores and biomass,

5 The same inference cannot be made about metal ores and industrial minerals due to the incomplete nature of trade statistics for these materials during the crucial period immediately after 1992.

6 . To determine this latter, or assign "responsibility" for end consumption, an indicator like material footprint (MF) would better suited than DMC (Wiedmann et al. 2013). That is not, 
where DMC may appear an order of magnitude or more higher in the extracting economy than it does for the economy where the concentrated metal or biomass product is finally used. This effect is further illustrated in a recent study by Krausmann et al. (2013). This implies a major limitation on inferring detail about a nation's internal economic structure from EW-MFA indicators alone. Given this, the fact that shares of different material categories remained roughly constant between 1992 and 2008 does not necessarily preclude a significant reprimarization of the region's economies.

\section{<Insert Figure 4 around here>}

Figure 5 shows DMC disaggregated by the four material categories. While broadly comparable in form to DE in Figure 3, DMC does not fully recover to 1992 levels any category. Since reaching their respective lows, the compounding annual rates of growth in DMC for each category were: biomass 3.1\% (1998-2008), construction minerals $8.1 \%$ (1997-2008), fossil fuels $1.7 \%$ (1998-2008), metal ores and industrial minerals 3.3\% (1996-2008). The stability of the relative shares of DMC accounted for by different categories of materials at the beginning and end of the time period is also apparent on inspection of Figure 5, however it should be noted that the regional trend heavily influenced by the trend for Russia alone, which accounted for almost $60 \%$ of the regional total. Considerably more variation can be seen for the selected individual countries examined later. 
2

Figure 6 shows materials intensity (MI) for the EECCA region, and the trend seen indicates that the region became much more efficient at converting materials inputs into GDP over the study period.

MI decreased over the full study period at a rate of approximately $2.8 \%$ compounding per annum, to less than $6.5 \mathrm{~kg} / \$ \mathrm{US}$ in 2008 . The rate of improvement remained strong even in the later part of the period at over $2.5 \%$ p.a. from 2000 to 2008 . This contrasts with the trend seen for the rest of the world, where MI was largely static when averaged over the full period, and has been deteriorating since 2000. This achievement at the regional level might in part reflect one-off opportunities available to increase efficiencies in economies which may have started the period with considerable negative value-adding ${ }^{7}$ in major industrial sectors (Thornton 1996, Simon 1996). Despite the rapid improvement in the EECCA region's performance, by 2008 it still consumed roughly 3.7 times the world average DMC per \$US of GDP generated. Furthermore, there was no single year over the period 1992 to 2008 where the regional GDP grew while total DMC decreased.

<Insert Figure 6 around here>

\subsection{Material Use Trends in Three Selected Economies}

In this section we concentrate on the changes seen at the individual national level for a selection of three successor states. At this level, we would expect the different 
natural endowments of each state to affect their development paths, as they were forced to function as individual states in a globalized economy, rather than as constituent states in the integrated economic whole that was the Soviet Union.

The largest successor state, Russia, was not selected for individual study because it is sufficiently large a component of the region that its profile is broadly similar to that described for the region as a whole ${ }^{8}$. The three states selected were Kazakhstan, Tajikistan, and Ukraine. These three nations encompass a range of very different material flows profiles. Using the six-type country classification set out by Krausmann et al. (2008), used as guidance to a country's socio-metabolic profile, three country typologies are covered: low population density industrial countries of the Old World (Kazakhstan), and high population density industrial countries of the Old World (Ukraine), and high population density developing countries (Tajikistan) ${ }^{9}$. For this study it is further asserted that Kazakhstan has high relative natural resource endowment, Ukraine a high to moderate endowment, and Tajikistan very low endowment. The justification for this is provided in the supporting information S1.

In Figure 7 we see that there are great disparities in affluence (GDP per-capita) between the selected states, and that these disparities increased over the period studied. Of the three, all began the period poorer than the EECCA average of $\$ 1,560$, marginally so in the case of Kazakhstan and significantly so in the case of Ukraine. Tajikistan was very poor, at around $17 \%$ of the regional average and broadly comparable to nations such as Sudan and Bangladesh at that time. Of the

8 Russia accounted for 59\% of regional total DMC in 2008.

9 If we took the aggregated status of the USSR as the starting point, then all successor states would be classified as "industrial", however the DMC profile of Tajikistan at the beginning of the study period has biomass-to-mineral ratios more typical of an advanced agrarian society rather than an industrial one. This reclassification is further warranted by Tajikistan's very low GDP per capita. 
three nations, only Kazakhstan finished the period significantly more affluent then it entered it, with Tajikistan actually poorer in 2008 than 1992, although all three recovered strongly from the depths of the post-Soviet era contraction. ${ }^{10}$

\section{<Insert Figure 7 around here>}

Figure 8 tracks the disparate performances of the case selected nations with regard to MI. All three nations managed to improve their MI, although only Kazakhstan performed better than the regional average, halving the amount of materials used to generate a dollar of GDP over the period. It is noteworthy that the order of performance in decreasing MI was the same as the order of performance in increasing GDP. This prompted an additional exercise to test the relationship between reduction in MI and increased GDP for all 12 regional countries, with interesting results discussed in section 4 below.

\section{<Insert Figure 8 around here>}

Figure 9 shows Kazakhstan's DMC per capita and PTB per capita. Both were the highest of the three focus countries, with PTB showing large net exports. Furthermore, the relative decrease in DMC was the smallest across the full time period, so that by 2008 it remained at $87 \%$ of the level it had been in 1992 . The change in PTB over the period was dominated by a tripling of net exports of fossil fuels (in per capita terms), while net exports of metal ores also expanded. The

10 If we use PPP measures of GDP instead of exchange rate based, GDP per capita for each of the three focus countries is much higher, and the disparity between them narrows, but the overall relativities and pattern over time remains the same. 
relative shares of all three non-biomass categories of DMC expanded at the expense of biomass, which decreased from $36 \%$ in 1992 to $27 \%$ in 2008, however when the decrease in total DMC tonnage per capita over the period is taken into account, we see that total DMC of both biomass and fossil fuels contracted. The relative contraction in fossil fuels was small compared to the other two focus countries, however, and Kazakhstan remained a highly fossil fuel-intensive economy. DMC per capita of metal ores and industrial minerals increased by $6 \%$ between 1992 and 2008, with construction minerals also slightly higher in 2008 than 1992, having peaked in 2007, immediately before the GFC of 2008.

The overall magnitude of DMC per capita and the relative shares of different categories for Kazakhstan are consistent with the socio-metabolic regime of an industrialized county, but its PTB indicates that it is becoming increasingly reliant on exports of fossil fuels in particular. This latter may be significant when we consider the relatively good performance of Kazakhstan in improving its MI. As most of the mass of fossil fuels is still embodied in the form in which they are extracted (Schandl and West 2012 ), very little of the fossils fuels extracted and exported afterwards will show on a countries DMC account, while all of the income generated will show in GDP, boosting apparent MI. It is thus likely that much of Kazakhstan's early improvements in MI and growth in GDP accrued from simply diverting fossil fuels previously used in relatively inefficient domestic industries to export markets, while strong increases in fossil fuel prices from around 2002 on would have boosted performance in the latter years. 
Tajikistan's DMC per capita and PTB per capita are shown in figure 10, and forms a stark contrast with that for Kazakhstan. Tajikistan's DMC per capita was the lowest for any of the three focus countries, finishing the period at 2.8 tonnes per capita. Tajikistan was not a significant net exporter of any major material category in any year, and heavily reliant on imports for its fossil fuel requirements. This lack of significant exports and associated foreign exchange income may explain the severity of the contraction in fossil fuel usage seen, as Tajikistan was exposed to market prices for imports. Fossil fuel consumption remained suppressed in subsequent years, at one third of 1992 levels in 2008. This contrasts with biomass, which had returned to 1992 levels by 2008 in absolute terms, and had greatly increased its relative share from $60 \%$ to $80 \%$. Non-zero fuel wood is recorded for Tajikistan's in FAO (2011a) for the first time in 2004, perhaps reflecting increasing substitution for expensive imported fossil fuels, however this accounted for less than $1 \%$ total biomass. While DMC of biomass returned to pre-contraction levels, imports of biomass decreased by $56 \%$, consistent with a country increasingly unable to pay for imports. Construction minerals, which are indicative of investment into fixed infrastructure, declined profoundly during the main contraction period, from 0.85 to 0.03 tonnes per capita in 1997, before recovering to 0.49 by 2007 . The subsequent sharp decline of DMC in construction minerals in 2008 may indicate that even though its PTB indicates minor trade integration with the global system compared to the other focus countries, Tajikistan was impacted as rapidly by the GFC as Kazakhstan..

For Tajikistan, the total magnitude of DMC and the relative shares of different DMC categories is consistent with those of developing countries such as Cambodia and Nepal in UNEP (2013b), while material productivity is even lower than for 
those countries. The combination of low DMC and very low material productivity indicates to a very low material standard of living.

\section{<Insert Figure 10 around here>}

Ukraine's DMC per capita and PTB per capita are shown in figure 11, and in some ways appears intermediate between the profiles of the other two focus countries, with total DMC around one half that of Kazakhstan, and displaying a mixed trading status i.e. a net importer of fossil fuels, and a net exporter of the other 3 categories, most notably of metal ores and industrial minerals. DMC per capita contracted strongly and by 2008 had only recovered to $73 \%$ of its 1992 level, but at 11.1 tonnes per capita was comparable to the World average of 10.5 tonnes. The contraction in DMC of fossil fuels was modest in comparison to that seen for Tajikistan. This may reflect a better ability to pay for continued imports of fossil fuels relative to Tajikistan, supported by growth in its other materials exports, and also a limited ability to substitute locally produced fossil fuels (notably coal) for imports. The PTB panel appears consistent with this, in that net fossil fuel imports per capita remained relatively stable after the initial contraction, while fairly consistent growth in net exports for all other categories continued over the postcontraction period $^{11}$.

Of the four categories of DMC, only biomass showed a marginal increase in tonnage per capita over the period, however as all other categories decreased, this translated into a major expansion in biomass' share of total DMC, from $26 \%$ in 1992 to $38 \%$ in 2008. The DMC pattern for Ukraine is thus one which might

11 The total absence of exports of metals ores and industrial minerals prior to 1996 is unlikely to reflect the true situation. Statistics on trade in this category for former Soviet Union nations for the period 1992 - 1995 are generally poor to non-existent. 
indicate a country becoming less industrialized, with a higher proportion of its DE apparently being exported at an earlier stage in the value-adding chain. This indicates that less is being retained locally in infrastructure, and/or less is being transformed into more elaborately transformed manufactured goods for export or local consumption. The DMC of fossil fuels remained at levels typical of industrialized countries even after strong decreases in the post-Soviet contraction. It may be that the earlier high levels resulted from low or negative value-adding activity, so the apparent de-industrialization may just reflect the improvement in material productivity that we know (from Figure 8) has taken place.

\section{<Insert Figure 11 around here>}

\subsection{Drivers of material use}

To analyse the drivers of material use, we apply here a variant of the IPAT framework proposed in Ehrlich and Holdren (1971). The implementation is identical to that outlined in West and Schandl (2013).

Table 1 shows changes in the drivers over the full study period for the three focus countries and the region as a whole. There are a couple of features of this study which contrast it with previous comparable studies for the Asia-Pacific (Schandl and West 2010) and Latin American (West and Schandl). Firstly, the population of the EECCA region as a whole contracted over time, and so ceteris paribus, would act to moderate environmental impacts over time. The second difference is that total DMC decreased over the study period as a whole, and so care must be taken in interpreting the figures given below e.g. where we see that $\Delta \mathrm{A}$ contributed $41 \%$ 
to the change in I for 1992-1998, this means that it acted to reduce DMC over that time, while for the period 1998 - 2008, its contribution of $224 \%$ acted to increase DMC.

For all three focus countries over the period 1992 - 1998 we can see that all became less affluent, and this acted to drive DMC lower, with this poverty effect most pronounced in Tajikistan. Similarly, as well as becoming poorer, all three countries became more efficient at generating GDP per tonne of material used. This also acted to drive DMC lower. Finally, Ukraine and Kazakhstan both experience population contractions, which further suppressed DMC. We see that over the post-Soviet era contraction period, increasing poverty was the strongest driver of decreases in DMC for the region as a whole, and for two out of the three focus countries.

During the period 1998-2008, we see that moderate to very strong improvements T continued, and acted as strong restraints on growth in DMC through this reexpansionary period. On the other hand, affluence increased strongly over the period, and was by far the strongest driver of increasing DMC for all focus countries and for the region as a whole. Population increased in two of the three focus countries, so driving DMC higher there, but in all cases except Tajikistan, the effect of population change was minor compared to the effects of A and T.

<Insert Table 1 around here> 
The EECCA region appears to have provided a unique experiment in how the natural endowments of nations and their initial economic structure can affect their development paths when suddenly exposed to global market forces. The insights resulting from this study extend and expand on previous analysis done for some non-Soviet of Eastern European economies e.g. for the Czech Republic, Hungary and Poland in Kovanda and Hak (2008).

Perhaps the clearest theme that can be identified from the post-Soviet MFA and material efficiency trends examined here is that EECCA was a region apart when it comes to both the initial inefficiency with which it employed natural resources to generate GDP, and that it has also since experienced improvements and (relative) dematerialization with an intensity not seen elsewhere. Despite these massive improvements in material efficiency, there would still appear to be room for major further improvements, as regional MI remains nearly four times World average levels, and over twice that of highly resource intensive regions such as Latin America. Perhaps surprisingly, it may be that the path to a more resource efficient future for some nations will pass, at least temporarily, through a period of serving increasingly as suppliers of natural resources to external economies. This is exactly what appears to be happening in economies such as Kazakhstan. Even if this is so, the special starting conditions of the region, (specifically, the widespread existence of negative value adding activities) cautions against reading too much into this. Reprimarization seems less likely to yield such improvements in resource efficiency in other settings. Research by Steinberger et al. (2013), for instance, indicated that a more typical pattern is for emerging / developing nations to demonstrate a stronger relative coupling between economic growth and DMC than industrialized nations (and so implicitly stronger than the world average coupling). 
The focus nations show successors to the Soviet Union following development paths and experiencing economic fortunes which are strongly influenced by their natural resource endowments and initial socio-metabolic structure. Kazakhstan, with its rich endowment of mineral wealth and lack of any significant import dependence from the outset, quickly found ready markets for its products in the global economy, and has outperformed economically. Tajikistan, in common with many high population density countries, had little natural wealth to call on, and its DMC profile in 1992 indicates that it began the period with an economic structure similar to the poorest agrarian societies. Its economic / development status at the end of the period, judged by GDP and DMC profile, was worse than in 1992, (but was improving). Ukraine's starting position appears much closer to Kazakhstan than Tajikistan, although it began the period dependent on considerable fossil fuel imports, and remained so. Its DMC profile in 2008 indicated a less industrialized society than in 1992, but improvements in material efficiency managed to restore its GDP to 1992 levels, in effect achieving the same with much less. The lack of any discernible impact of the GFC on Ukraine, compared to Kazakhstan and Tajikistan, perhaps indicates a nation which is less integrated with those regions most affected by the GFC. Given its position (closer to Western Europe, which was heavily impacted by the GFC, and more distant from East Asia, which was relatively unaffected) this is somewhat unexpected. Perhaps the Ukraine has retained stronger links to the EECCA region as a whole, which demonstrated a similar resilience to the GFC in 2008. Certainly at the time of writing the ability of the Ukraine to act entirely politically independent from Russia appears to be constrained. 
In the course of this study, it also became apparent that the trajectory of resource efficiencies following the abrupt dissolution of Soviet Union presented an opportunity to look for the effects of improving material efficiency on economic growth. Any clear manifestation of a positive link between increased material efficiency and stronger economic growth is relevant to both the debate on whether dematerialization is a net positive or negative for economic growth, and would also provide support for some measure of rebound effect ${ }^{12}$. As mentioned in section 3.2, the observed match between rankings of the three focus countries on improvement in MI and GDP growth suggested a broader and more formal test for correlation using data for all 12 countries. The subsequent regression of growth in GDP on reductions in MI, between 1992 and 2008, yielded an $R^{2}$ of 0.59 (adjusted $R^{2}$ of $0.55)$ and significant at the $99 \%$ level $(p=0.0034$, see SI). While in no way proving causation, this initial result is very much what we would expect to see if much of the post contraction growth was driven by removing or reducing the inefficiencies of materials use in the preceding economic system. A natural follow up to this result would be testing this relationship in detail at an international level, using the comparable data sets prepared for the Asia-Pacific and for Latin America and the Caribbean, and also extending it to see if there is an independent link between DMC and improved resource efficiency (after controlling for affluence), which is we would expect from rebound. At the time of writing, however, it was thought that careful consideration needed to go into how any such extensions should be conducted, to avoid descending into what could too easily become an exercise in mining for correlations. Conducting and reporting on a systematic investigation along these lines is intended as a next step.

12 Rebound effect is the tendency of efficiency gains to generate further demand, which in turn reduce the persistence of any initial reduction in materials or energy demand which resulted from the initial efficiency gains. A good review of the different types and degrees of rebound is contained in Jenkins et.al (2011). That work deals with rebound as it applies to energy consumption, however the underlying principle should apply to materials consumption as well. 
This research has been supported by the United Nations Environment Program regional office for Europe, and by the Austrian Science Fund, Project P21012-G11 Glometra . The authors would also like to thank Ron Witt of UNEP's Division of Early Warning and Assessment for his input, and David Fleming and Tim Baynes of CSIRO's Ecosystem Sciences Division for performing internal review prior to submission and for their suggestions.

References

Baccini, P., Brunner, P.H., 1991. Metabolism of the Anthroposphere, first ed. Springer-Verlag. Bartelmus, P., 2007. SEEA-2003: Accounting for sustainable development? Ecological Economics 61, 613-616. 1212-1217. European Commission, Food and Agriculture Organization, International Monetary Fund, Organisation for Economic Co-operation and Development, United Nations, 
World Bank, 2012. System of Environmental Economic Accounting - Central Framework . White cover publication, pre-edited text subject to official editing. FAO, 2011a. Subscribers section - Bulk downloads - Forestry . Food and agriculture organization of the United Nations.

Fischer-Kowalski, M., Haberl, H., 2007. Socioecological Transitions and Global Change: Trajectories of Social Metabolism and Land Use. Edward Elgar, Cheltenham.

Fischer-Kowalski, M., Krausmann, F., Giljum, S., Lutter, S., Mayer, A., Bringezu, S., Moriguchi, Y., Schütz, H., Schandl, H., Weisz, H., 2011. Methodology and Indicators of Economy-wide Material Flow Accounting. Journal of Industrial Ecology 15, 855-876.

Gierlinger, S., Krausmann, F., 2012. The Physical Economy of the United States of America. Journal of Industrial Ecology 16, 365-377.

Haberl, H., Fischer-Kowalski, M., Krausmann, F., Weisz, H., Winiwarter, V., 2004. Progress towards sustainability? What the conceptual framework of material and energy flow accounting (MEFA) can offer. Land Use Policy 21, 199-213. Jenkins, J., Nordhaus, T., Shellenberger, M., 2011. Energy Emergence: Rebound and Backfire as Emergent Phenomena. Breakthrough Institute.

Kovanda, J., Hak, T., 2008. Changes in Materials Use in Transition Economies. Journal of Industrial Ecology 12, 721-738.

Kovanda, J., Hak, T., 2011. Historical perspectives of material use in Czechoslovakia in 1855-2007. Ecological Indicators 11, 1375-1384. Krausmann, F., Fischer-Kowalski, M., Schandl, H., Eisenmenger, N., 2008. The Global Sociometabolic Transition. Journal of Industrial Ecology 12, 637-656. 
Krausmann, F., Gingrich, S., Nourbakhch-Sabet, R., 2011. The Metabolic

Transition in Japan. Journal of Industrial Ecology 15, 877-892.

Krausmann, F., Richter, R., Eisenmenger, N., 2013. Resource use in small Island states: Material flows in Iceland and Trinidad and Tobago 1961-2008. Journal of Industrial Ecology In Press.

Schaffartzik, A., Mayer, A., Gingrich, A., Eisenmenger, N., Loy, C., Krausmann, F., forthcoming. The Global Metabolic Transition: Regional Patterns and Trends of Global Material Flows, 1950-2010

Schandl, H., West, J., 2010. Resource use and resource efficiency in the AsiaPacific region. Global Environmental Change - Human and Policy Dimensions 20, 636-647.

Schandl, H., West, J., 2012. Material Flows and Material Productivity in China, Australia, and Japan. Journal of Industrial Ecology 16, 352-364.

Simon, G., 1996. The End of the Soviet Union: Causes and Relational Contexts, German Foreign Affairs Review. ISN Center for Security Studies, Zurich.

Steinberger, J.K., Krausmann, F., Getzner, M., Schandl, H., West, J., 2013. Development and Dematerialization: An International Study. PLoS ONE 8. Thornton, J., 1996. Structural Change in the Russian Far East: The Implications for Trade and Factor Markets. Atlantic Economic Journal 24, 208-227.

UNEP, 2011. Eficiencia en el uso de los recursos en América Latina: Perspectivas e implicancias económicas. United Nations Environment Program, Panama city. UNEP, 2013a. Recent trends in material flows and resource productivity in Asia and the Pacific. United Nations Environment Program. UNEP, 2013b. Material Use and Resource Productivity in Latin America and the Caribbean United Nations Environment Program. 
1

2

3

4

5

6

7

8

9

Weisz, H., Amann, C., Eisenmenger, N., Krausmann, F., Hubacek, K., 2004.

Development of material use in the EU-15: 1970-2001: Types of materials, crosscountry comparison and indicator improvement. IFF-Social Ecology, Vienna.

West, J., Schandl, H., 2013. Material use and material efficiency in Latin America and the Caribbean. Ecological Economics 94, 19-27.

Wiedmann, T.O., Schandl, H., Lenzen, M., Moran, D., Suh, S., West, J.,

Kanemoto, K., 2013. The material footprint of nations. Proceedings of the National Academy of Sciences.

World Bank, 2012. World Development Indicators 2012. World Bank. 


\begin{tabular}{|c|c|c|c|c|c|}
\hline & $\Delta l \%$ & $\begin{array}{l}\Delta \mathrm{I} \\
\text { (million tons) }\end{array}$ & $\Delta \log \mathrm{P}$ & $\Delta \log A$ & $\Delta \log T$ \\
\hline \multicolumn{6}{|l|}{$1992-1998$} \\
\hline Kazakhstan & $-43 \%$ & -200.3 & $16 \%$ & $41 \%$ & $43 \%$ \\
\hline Tajikistan & $-51 \%$ & -10.6 & $-12 \%$ & $106 \%$ & $6 \%$ \\
\hline Ukraine & $-57 \%$ & -450.3 & $5 \%$ & $79 \%$ & $17 \%$ \\
\hline EECCA & $-42 \%$ & -1860.0 & $1 \%$ & $66 \%$ & $33 \%$ \\
\hline \multicolumn{6}{|l|}{$1998-2008$} \\
\hline Kazakhstan & $40 \%$ & 111.2 & $14 \%$ & $224 \%$ & $-138 \%$ \\
\hline Tajikistan & $91 \%$ & 9.1 & $18 \%$ & $98 \%$ & $-15 \%$ \\
\hline Ukraine & $50 \%$ & 170.6 & $-18 \%$ & $164 \%$ & $-47 \%$ \\
\hline EECCA & $45 \%$ & 1230.0 & $-3 \%$ & $175 \%$ & $-72 \%$ \\
\hline
\end{tabular}

Legend: $\mathrm{I}=\mathrm{DMC}, \mathrm{P}=$ population, $\mathrm{A}=\mathrm{GDP} /$ capita and $\mathrm{T}=\mathrm{DMC} / \mathrm{GDP}$

Table 1: Major drivers of the change in domestic material consumption for all countries in the EECCA region over the period 1992 to 2008 


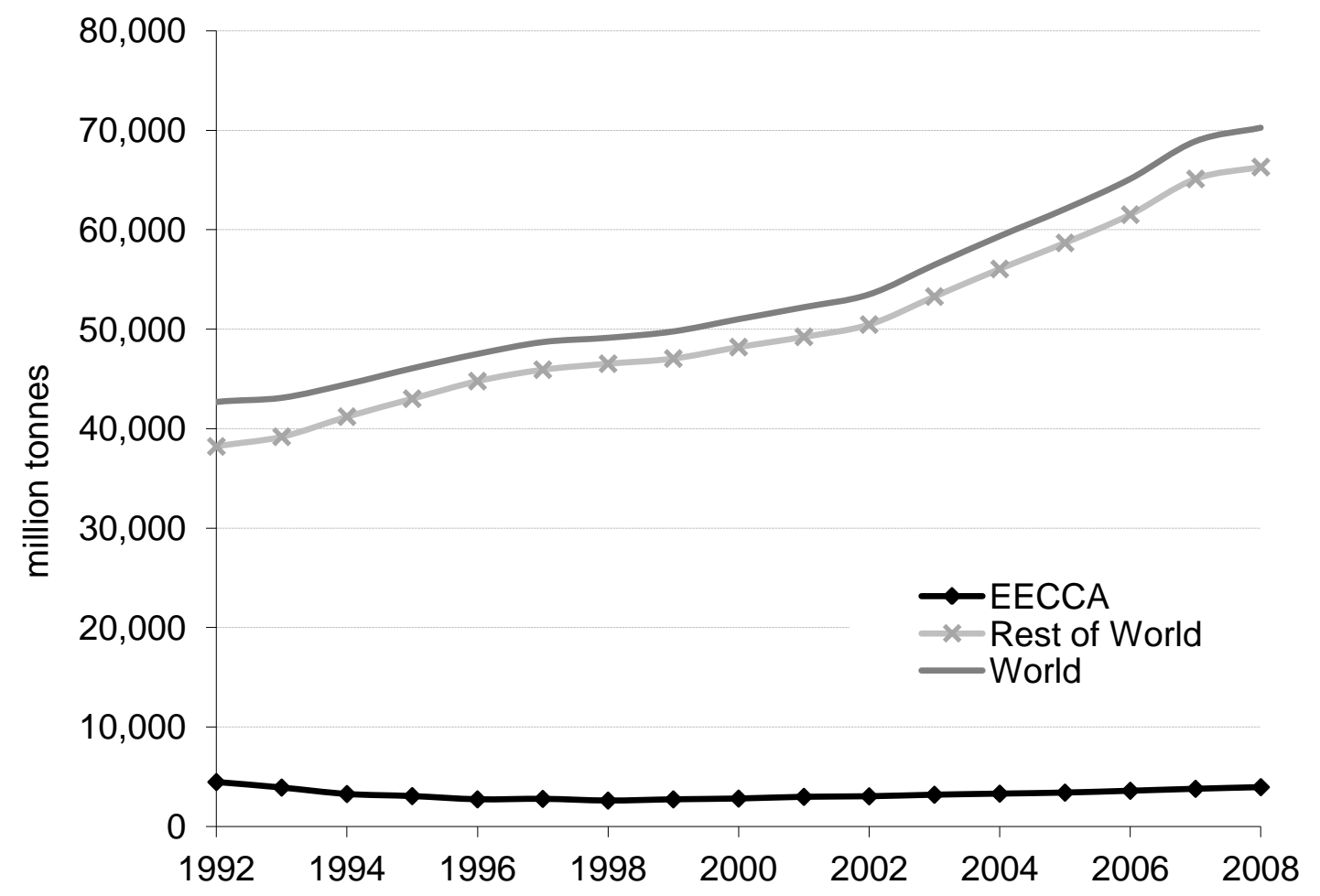

Figure 1 Domestic material consumption for EECCA, Rest of the World, and World, for 1992 to 2008 


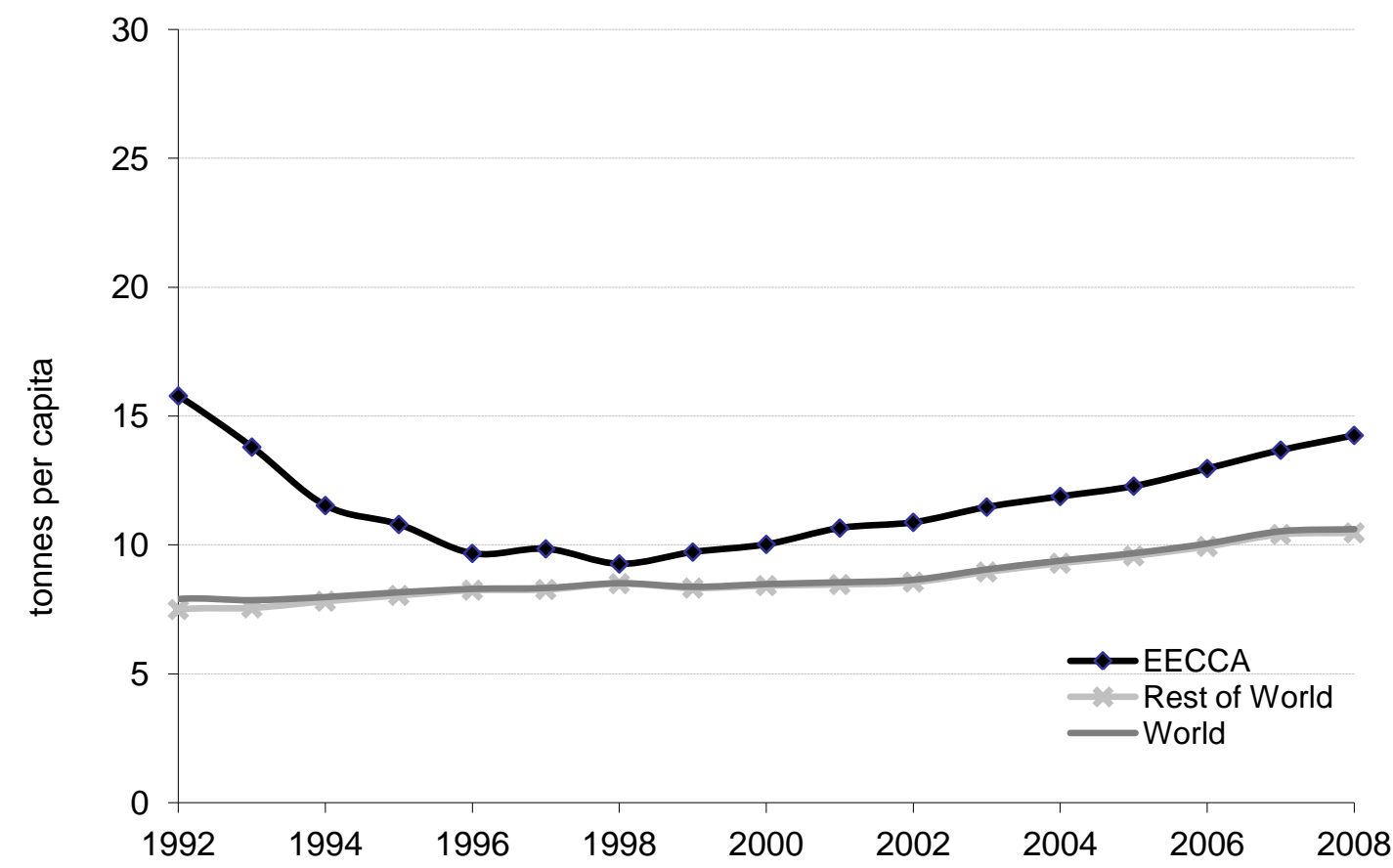

Figure 2 Domestic materials consumption per capita for EECCA, Rest of the World, and World, for 1992 to 2008 


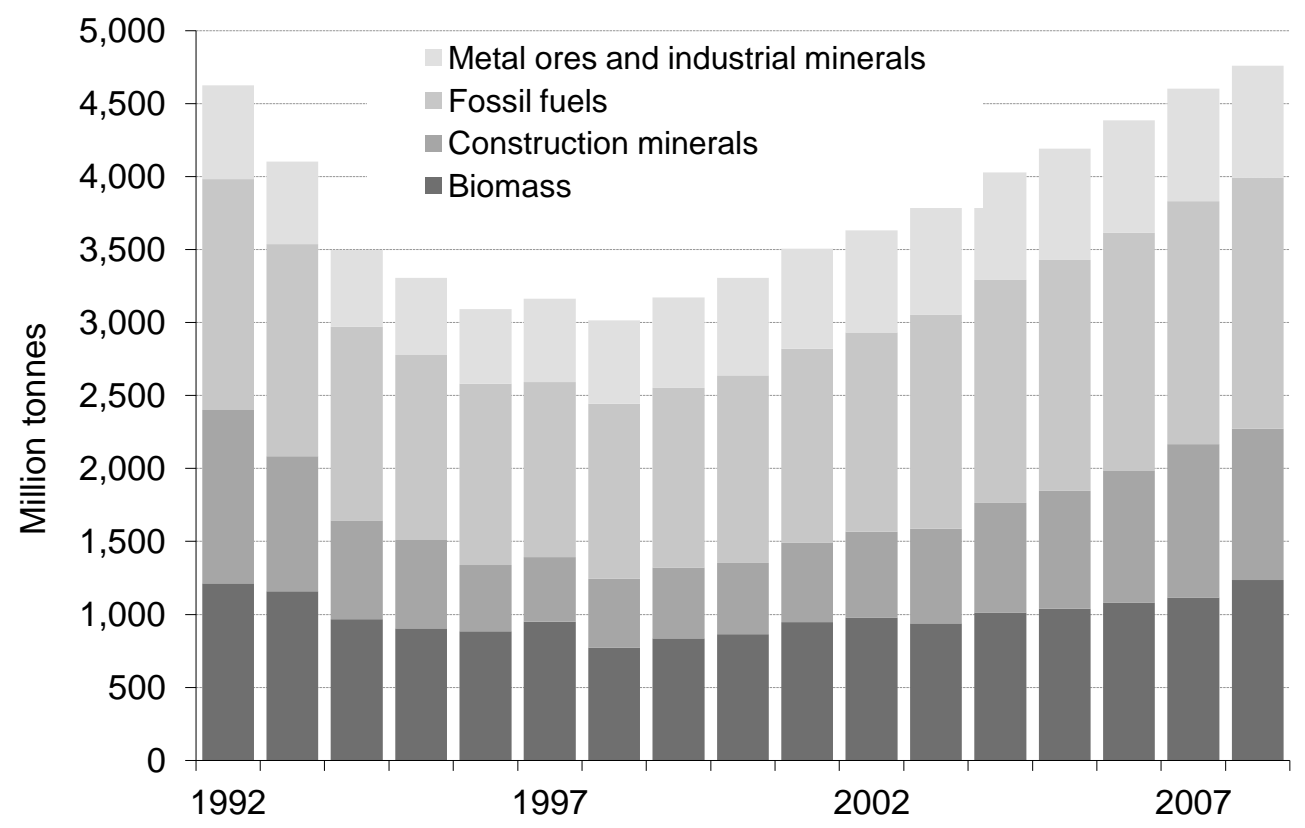

Figure 3: Domestic extraction in the EECCA region by major category of material for the years 1992 to 2008 


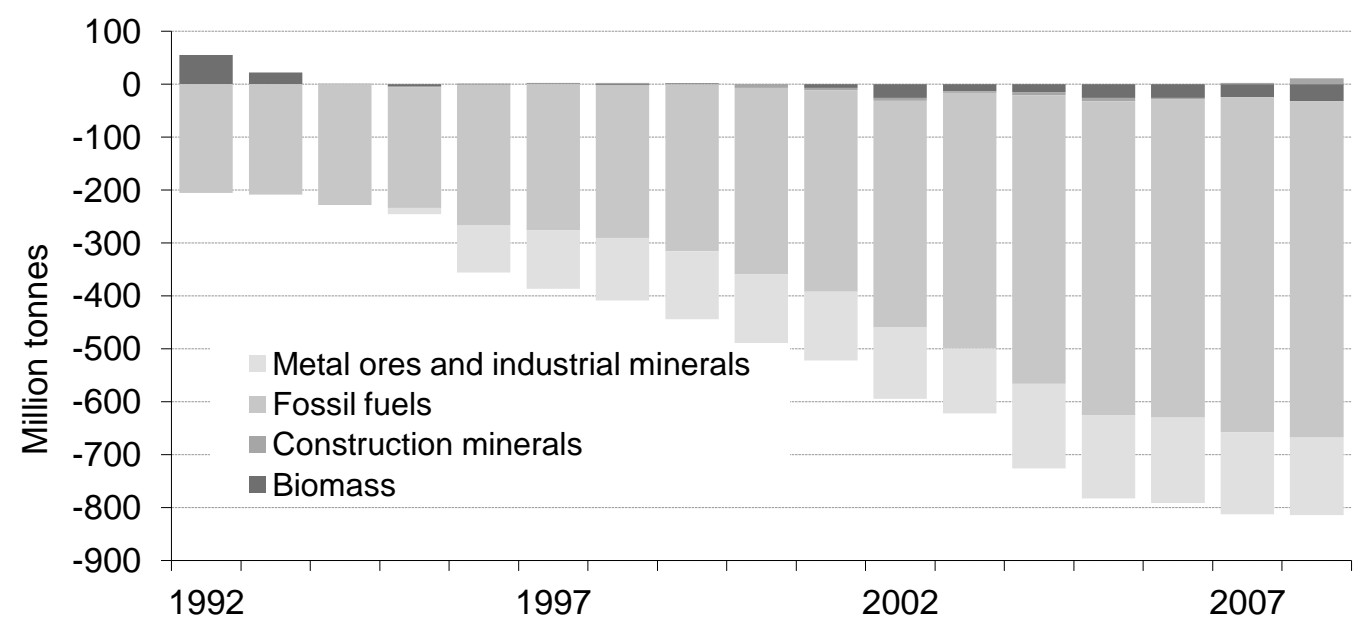

Figure 1: Physical Trade Balance for the EECCA region by major category of material for the years 1992 to 2008 


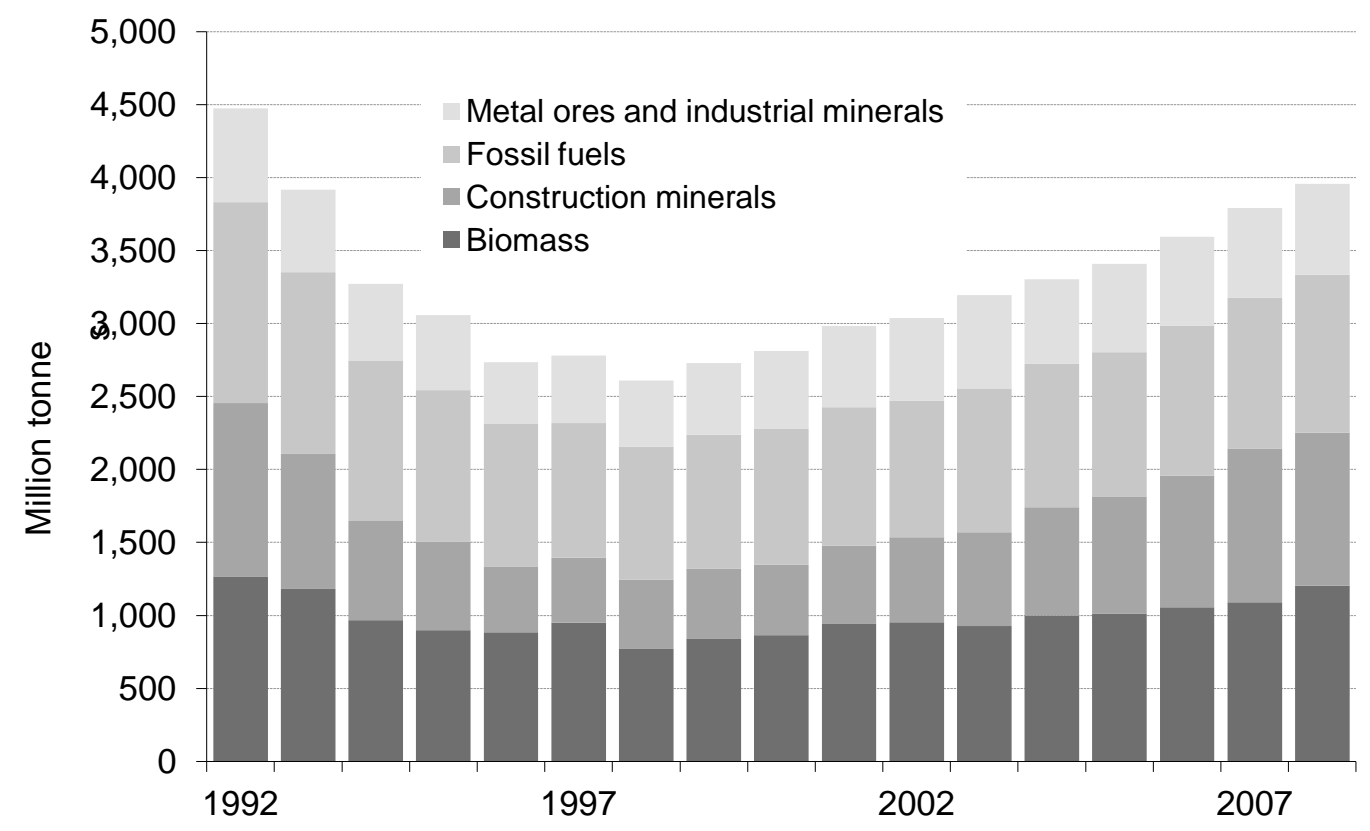

Figure 5: Domestic material consumption in the EECCA region by major category of material for the years 1992 to 2008 


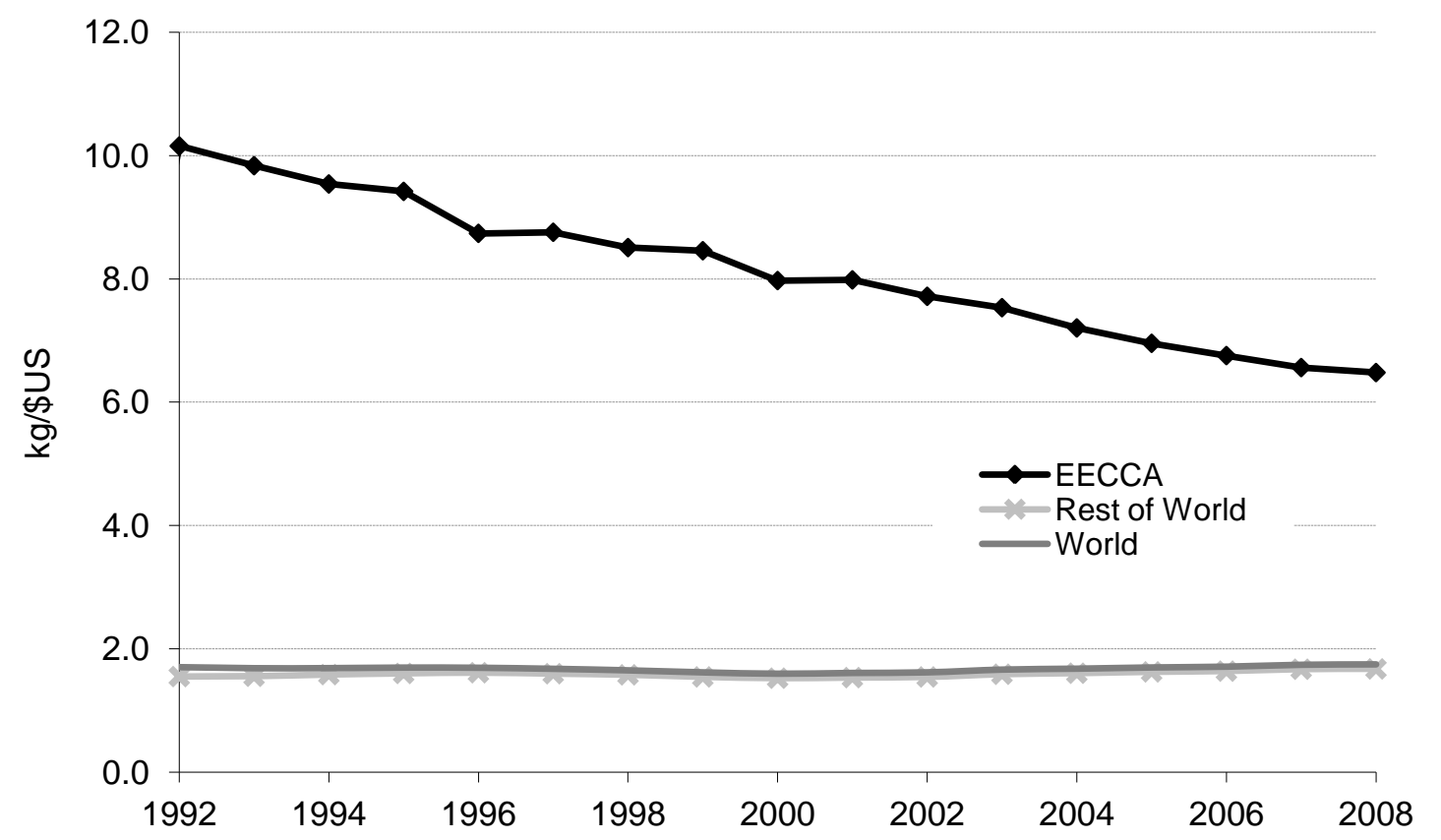

Figure 6: Domestic materials consumption per \$US of GDP (exchange rate based, constant year 2000) for the EECCA region, Rest of the World and World, for the years 1992 to 2008 


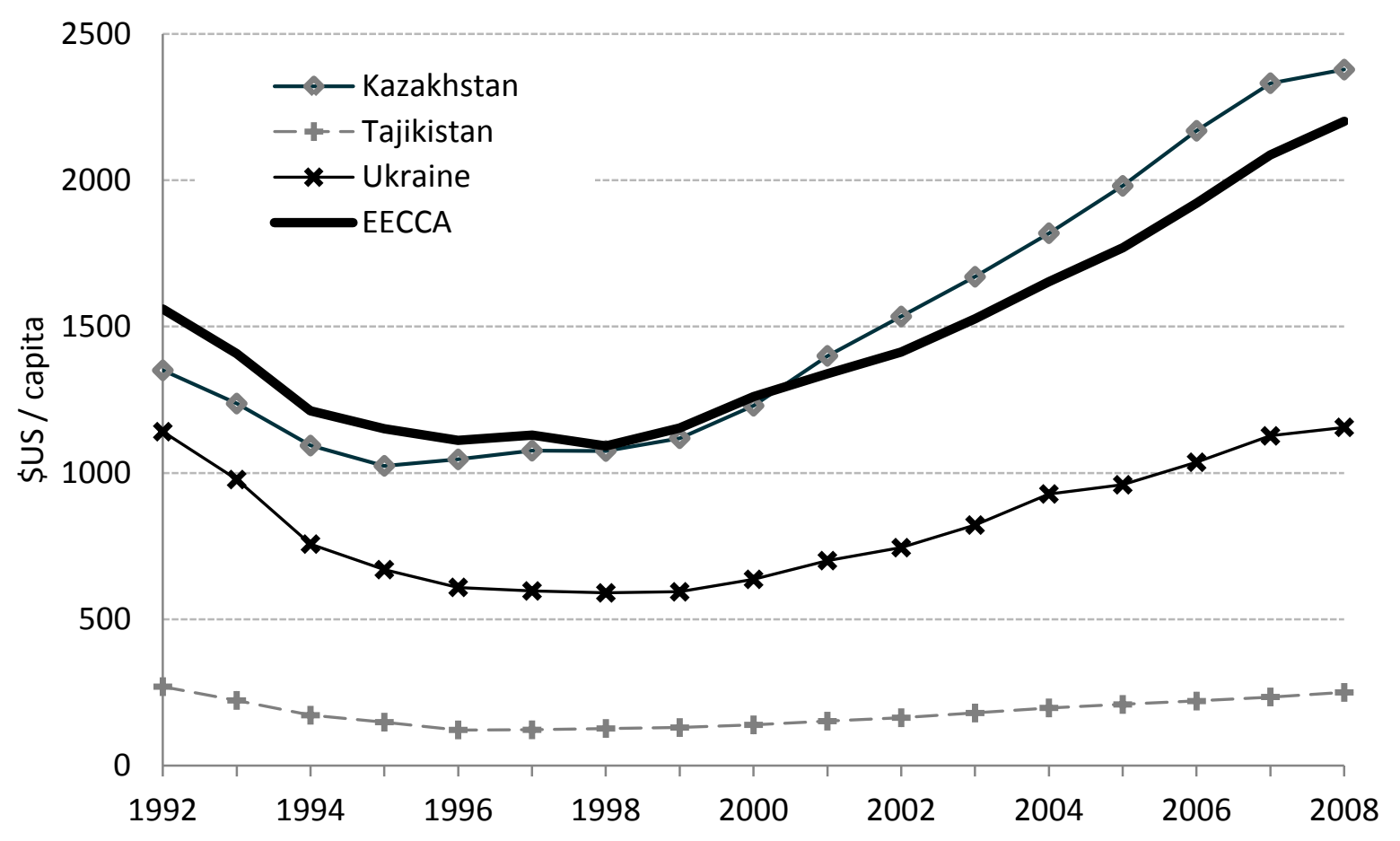

Figure 7: GDP per capita for Kazakhstan, Tajikistan, Ukraine and the EECCA Region. GDP used is exchange rate based constant year 2000 \$US 


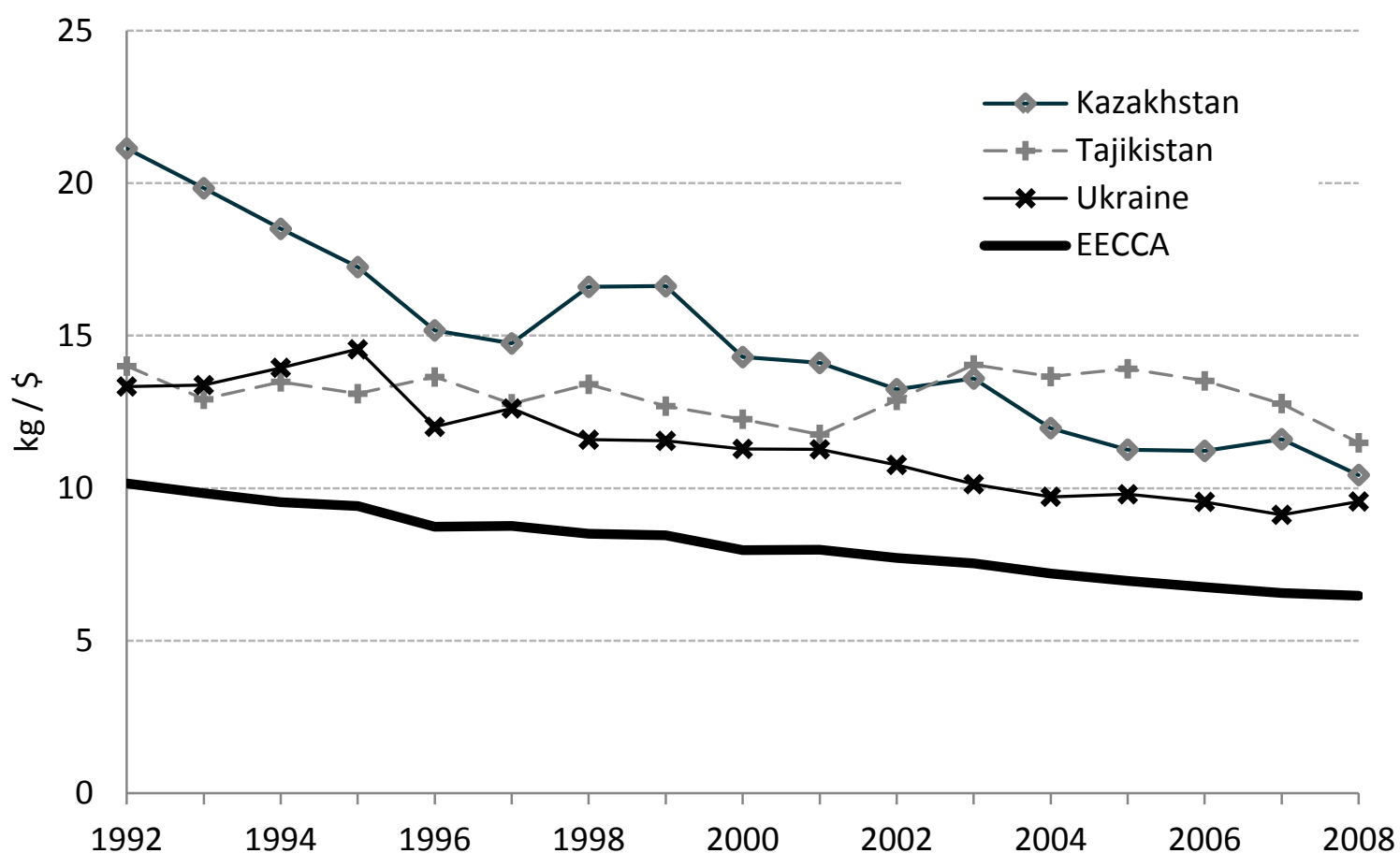

Figure 8: Material Intensity for Kazakhstan, Tajikistan, Ukraine and the EECCA Region. GDP used is exchange rate based constant year 2000 \$US 

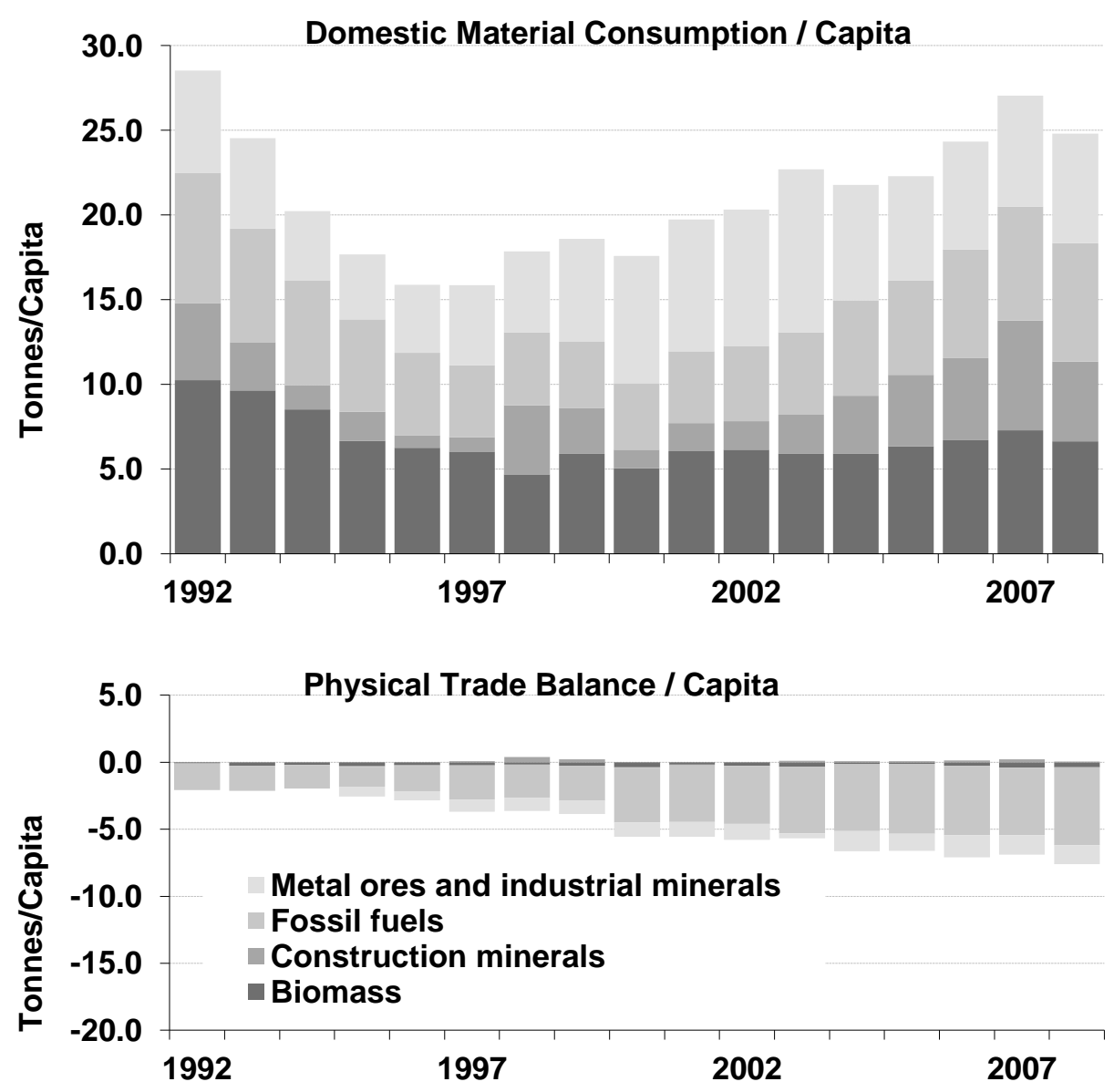

Figure 9: DMC per capita and PTB per capita for Kazakhstan for the period 1992 to 2008 

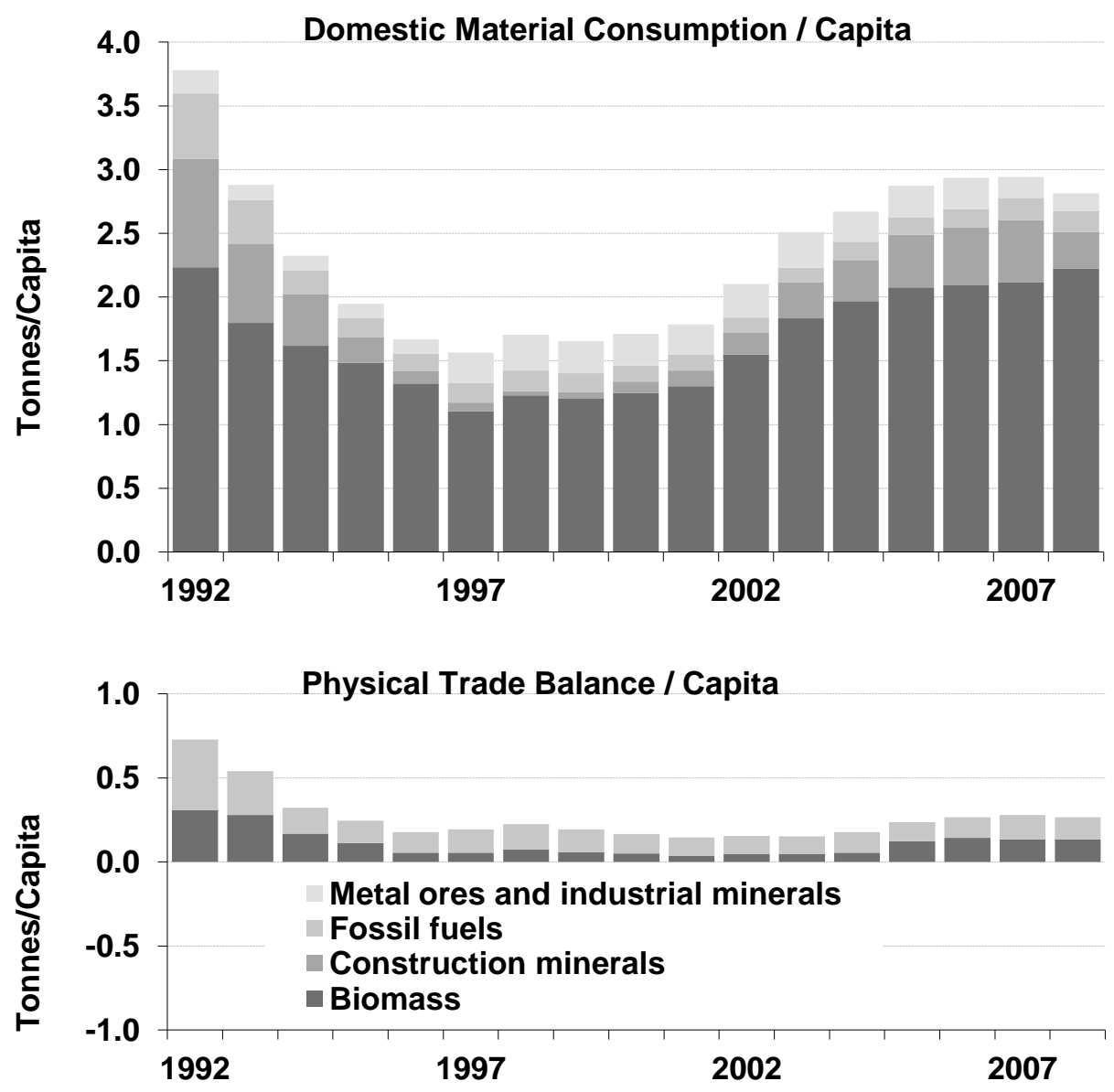

Figure 10: DMC per capita and PTB per capita for Tajikistan for the period 1992 to 2008 

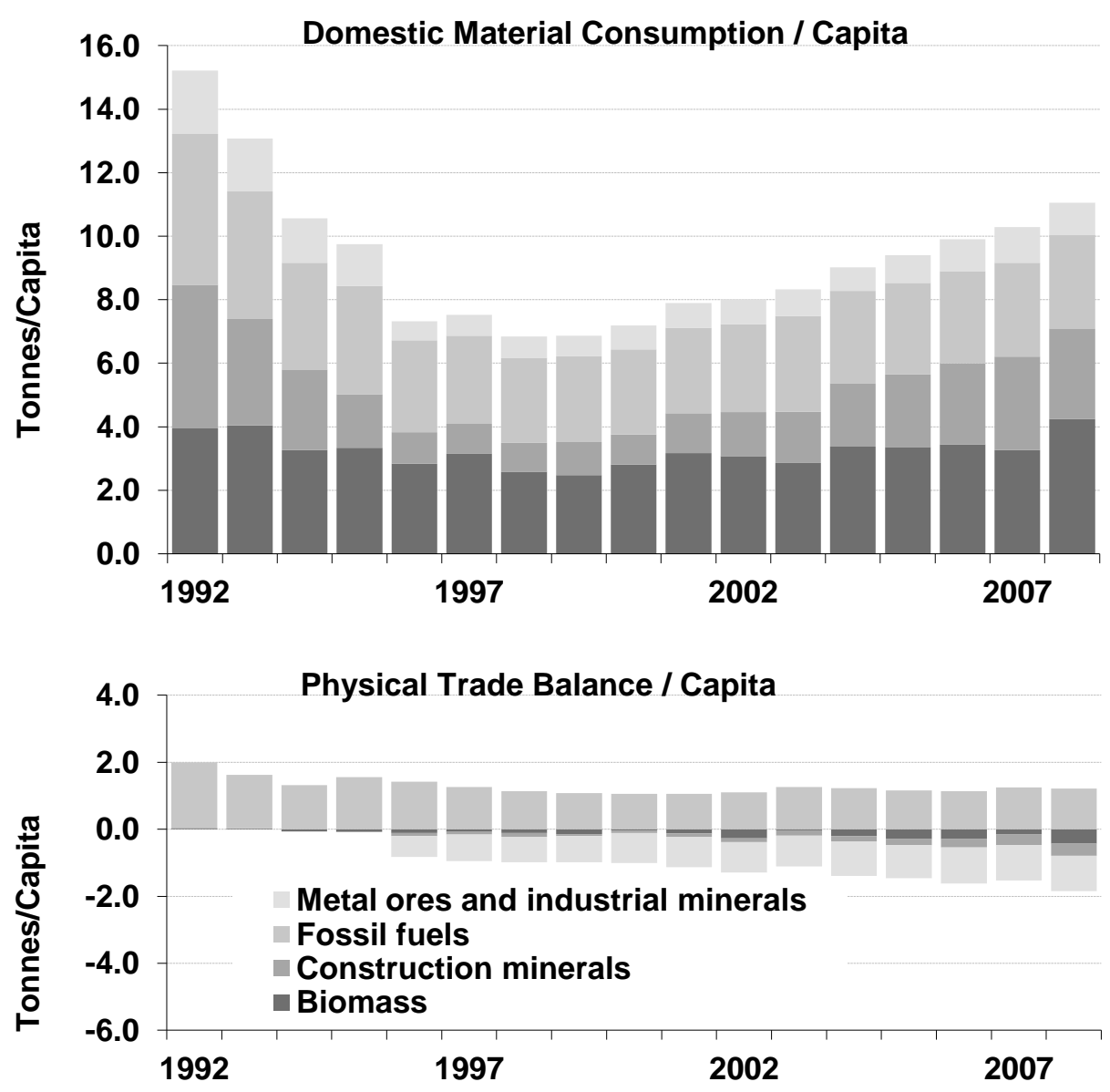

Figure 11: DMC per capita and PTB per capita for Ukraine for the period 1992 to 2008 